\title{
CARACTERIZAÇÃO MORFOLÓGICA DE GENÓTIPOS DE Manihot esculenta Crantz OBTIDOS VIA SEMENTES
}

\author{
Odila Friss Ebertz'; Edwin Camacho Palomino². \\ ${ }^{1}$ Universidade Federal do Oeste do Pará (UFOPA), Santarém, Pará, Brasil, odyla16@hotmail.com \\ 2 UFOPA, Santarém, Pará, Brasil, edwincamacho2@hotmail.com
}

RESUMO: O Brasil, por ser o provável centro de origem da espécie Manihot esculenta, apresenta alta variabilidade genética. Apesar da espécie ser reproduzida comercialmente de forma vegetativa, pode também se reproduzir via sementes sexuadas. As sementes são utilizadas essencialmente em programas de melhoramento genético, por promoverem variabilidade indispensável para se fazer seleção de novos genótipos de interesse agronômico. O objetivo deste estudo foi caracterizar os genótipos a partir de descritores morfológicos baseados no caule, folhas, pecíolos, e arquitetura da planta dos indivíduos de macaxeira obtidos através de sementes resultantes de cruzamentos ao acaso entre indivíduos de uma coleção local de germoplasma. Os resultados indicam ampla variabilidade para a maioria dos descritores, sendo somente a classe proeminência das cicatrizes foliares característica presente em todos os genótipos. Destaca-se também, o alto coeficiente de variação em relação ao descritor altura da primeira ramificação.

PALAVRAS-CHAVE: Manihot esculenta, Morfologia, Sementes, Variabilidade.

\section{MORPHOLOGICAL CHARACTERIZATION OF GENOTYPES OF Manihot esculenta Crantz OBTAINED BY SEEDS}

ABSTRACT: Brazil, being the probable center of origin of the species Manihot esculenta, high genetic variability. Although the species is reproduced commercially in a vegetative way, can also reproduce via seeds sexuates. Seeds are mainly used in genetic improvement, because they promote the variability that is indispensable to selection of new genotypes of agronomic interest. The objective of this study was characterize the genotypes from stem-based morphological descriptors, leaves, petioles, and plant architecture of the macaxeira individuals obtained through from random crosses between individuals in a germplasm site. The results indicate wide variability for most descriptors, being only the class prominence of the foliar scars characteristic of all genotypes. It is also worth noting the high coefficient of variation in relation to the descriptor height of the first branch.

KEYWORDS: variability; Manihot esculenta; seeds; morphology. 


\section{CARACATERIZACION MORFOLOGICA DE GENOTIPOS DE Manihot esculenta Crantz OBTENIDOS VÍA SEMILLAS}

RESUMEN: Brasil, por ser el probable centro de origen de la especie Manihot esculenta, presenta una alta variabilidad genética. A pesar de que la especie se reproduce comercialmente de forma vegetativa, puede también reproducirse a través de semillas sexuadas. Las semillas se utilizan esencialmente en programas de mejoramiento genético, por promover la variabilidad indispensable para hacerse selección de nuevos genotipos de interés agronómico. El objetivo de este estudio fue caracterizar los genotipos a partir de descriptores morfológicos basados en el tallo, hojas, pecíolos, y arquitectura de la planta de los individuos de macroneira obtenidos a través de semillas resultantes de cruzamientos al azar entre individuos de una colección local de germoplasma. Los resultados indican una amplia variabilidad para la mayoría de los descriptores, siendo solamente la clase prominente de las cicatrices foliares la característica presente en todos los genotipos. Se destaca también, el alto el coeficiente de variación en relación al descriptor altura de la primera ramificación.

PALABRAS CLAVE: Manihot esculenta, Morfologia, Semillas, Variabilidad.

\section{INTRODUÇÃO}

Manihot esculenta Crantz,

(Euphorbiaceae), espécie com alta capacidade de adaptação as mais diversas condições edafoclimáticas, sendo por isso, cultivada em mais de cem países constituindo a base da agricultura e alimentação de muitas populações (ARAÚJO; ARRUDA JUNIOR, 2013).

Segundo o Departamento de Economia Rural da Secretaria de Estado da Agricultura e do Abastecimento SEAB/DERAL (2015), o Brasil, mesmo com a menor produção dos últimos anos, com apenas 21 milhões de toneladas no ano de
2013, ainda representa 75\% da produção da América do Sul é o quarto maior produtor mundial, ficando atrás somente da Nigéria, Tailândia e Indonésia. Dentre os estados produtores de mandioca do Brasil, destaca-se o Pará como maior produtor, porém com produtividade em Kg/ha inferior aos estados do Paraná, São Paulo, Mato Grosso do Sul, Santa Catarina, Rio Grande do Sul e Mato Grosso. A baixa produtividade do estado está relacionada com a deficiência no uso de tecnologias e de material genético recomendado para a região. 
A produção de mandioca é classificada frequentemente em dois cenários, a produção de mandioca de mesa conhecida também por macaxeira que é comercializada in natura e a produção de mandioca para indústria, comercializada principalmente na forma de farinha para uso alimentar e a fécula, que, junto com seus derivados, é usada na alimentação humana, ou como insumos em diversos ramos industriais tais como o de alimentos embutidos, embalagens, filmes biodegradáveis, colas, mineração, indústria têxtil e farmacêutica (MEZETTE et al., 2009; VIERA et al., 2010; HENRIQUE et al., 2008).

A macaxeira caracteriza-se por apresentar baixo teor de compostos cianogênicos, pequena quantidade de fibras, com sabor e cor apreciados pelos consumidores, raízes uniformes, tanto no comprimento como no diâmetro, de fácil cozimento, boa durabilidade pós-colheita e facilidade de descascamento, sendo, portanto, consumida via úmida, sem exigir processamento industrial (MEZETTE et al., 2009; ZUIN et al., 2009).

A propagação de $M$. esculenta, vem sofrendo interferência humana ao longo da sua história evolutiva no processo de domesticação desta espécie, sendo gerados plantios clonais para fins comerciais. Entretanto, a mandioca continua se reproduzindo de forma sexuada por alogamia, favorecida pelo fato de as flores femininas localizadas na base da inflorescência se abrirem uma semana antes das flores masculinas presentes no ápice, mecanismo esse chamado de protogínia (SILVA et al. 2001; LARA et al., 2008). As sementes geradas destes cruzamentos, são responsáveis por promover a variabilidade genética e possibilitar a seleção de genótipos de maior importância agronômica pelos melhoristas, atuando muitas vezes como filtros para patologias virais associadas à propagação vegetativa.

De acordo com Nolasco (2011), mesmo a mandioca sendo uma cultura capaz de adaptar-se a diferentes condições edafoclimáticas, apresenta alta interação dos híbridos com o ambiente, o que resulta em diferentes comportamentos de um mesmo genótipo em regiões distintas, portanto, o mais indicado seria o desenvolvimento de material genético específico para cada região produtora. A 
espécie em questão apresenta elevada segregação na primeira geração após a hibridação, podendo ser identificado, a partir da descrição morfológica, um híbrido superior, o qual deve ser selecionado e fixado por meio da propagação vegetativa, o que é vantajoso em trabalhos de melhoramento que visam o desenvolvimento de cultivares adaptadas a região (LARA et al., 2008).

Segundo estudos (BURLE; OLIVEIRA, 2010; CAMPOS et al., 2010; NICK et al., 2010; TEIXEIRA et al., 2014), a caracterização morfológica consiste em tomar dados para descrever, diferenciar e identificar acessos de uma mesma espécie e pode ser feita com base em observações ou mensurações de caracteres morfológicos diferenciáveis visualmente, sendo obrigatoriamente a primeira caracterização realizada em germoplasma após sua inserção na coleção, visto que estas características são altamente herdáveis, controladas por poucos genes e portanto apresentam baixa interação genótipo/ambiente, facilitando o trabalho de seleção pelos melhoristas.
- presente projeto de pesquisa, consiste na primeira caracterização morfológica da primeira geração de genótipos provenientes de cruzamentos ao acaso entre indivíduos de uma coleção de germoplasma local composta por 25 diferentes acessos que receberam nomenclatura vulgar pelos comunitários, prática comum em comunidades amazônicas onde os produtores nomeiam o material genético de acordo com características fenotípicas (GAMA, LUCAS \& LOBATO, 2015), objetivando verificar a existência de indivíduos com características desejáveis para posterior multiplicação destes no município de Santarém.

\section{MATERIAL E MÉTODOS}

Em outubro de 2015, foi realizada a coleta de frutos resultantes de cruzamento ao acaso em coleção de germoplasma local, com 25 acessos de $\mathbf{M}$. esculenta (Tabela 1) na comunidade Tabocal localizada na BR 163, km 22. Os frutos foram secos em temperatura ambiente para extração das sementes, contadas e semeadas em janeiro de 2016 em sementeira com substrato "terra 
preta" no Viveiro Experimental de

foram transferidas para tubetes e Produção de Mudas da Universidade permaneceram nestes, até o mês de abril Federal do Oeste do Pará - UFOPA. quando 318 indivíduos atingiram tamanho Foram obtidas 1.132 sementes. As e vigor adequados para transplante em plântulas originadas após a germinação campo.

Tabela 1. Coleção de germoplasma utilizado para a obtenção de sementes.

\begin{tabular}{cccccc}
\hline Número & Nome vulgar & Número & Nome vulgar & Número & Nome vulgar \\
\hline 1 & Água morna & 10 & Amarelona & 19 & Fécula Paraná \\
2 & Raimundinha & 11 & Olhino & 20 & Pão \\
3 & Vermelhinha & 12 & Cacau & 21 & Pereirinha \\
4 & Gaucha & 13 & Tabocal & 22 & Máximo \\
5 & Paço Branco & 14 & MT Terra Nova & 23 & Tabocal I \\
6 & Branquinha & 15 & MT Facinio & 24 & Tabocal II \\
7 & Camila & 16 & Curuai vermelha & 25 & Tabocal III \\
8 & Santarena & 17 & Buchudinha Mojú & & \\
9 & Roxa do Curudi & 18 & Mojú Branca & & \\
\hline
\end{tabular}

O transplante ocorreu, portanto, na manhã do dia dezoito de abril, tendo sido feito o transporte das mudas em caixas de papelão até a área do produtor rural, localizada na comunidade de Boa Esperança, Km 43 da PA 370. No plantio, foi utilizado espaçamento de $1 \times 1 \mathrm{~m}$ dispondo as mudas em dezesseis linhas com vinte covas cada. Durante a condução das plântulas foram realizadas duas adubações de cobertura e controle de plantas invasoras para evitar a matocompetição.
Foram feitas avaliações visuais dos descritores morfológicos como: cor da folha apical, pubescência do broto apical, forma do lóbulo central, cor do pecíolo, cor da folha desenvolvida, número de lóbulos, relação comprimento/largura do lóbulo central, comprimento do pecíolo, cor da nervura e posição do pecíolo em setembro de 2016 obedecendo a idade mínima estipulada por Fukuda \& Guevara (1998) em "Descritores morfológicos e agronômicos para a caracterização de mandioca (Manihot esculenta Crantz)", e 
em outubro foram avaliados descritores como: cor do córtex do caule, cor externa do caule, comprimento da filotaxia, cor da epiderme do caule, hábito de crescimento do caule, cor dos ramos terminais nas plantas adultas, altura da planta, altura da primeira ramificação, níveis de ramificação e tipo de planta.

\section{RESULTADOS E DISCUSSÃO}

Como já era esperado, os cruzamentos ao acaso resultaram em alta variabilidade genética, refletido nos fenótipos das plantas, justificado pela morfologia diversa existente entre os parentais. A frequência de cada classe fenotípica dentro dos descritores morfológicos qualitativos é apresentada na Tabela 2.

Para o descritor morfológico cor da folha apical, as classes verde arroxeada (37,81\%) e verde clara $(31,45 \%)$ apresentaram maior frequência entre os genótipos estudados, assim como os dados obtidos por Vieira et al. (2008) ao avaliar 356 acessos de mandioca do banco de germoplasma da Embrapa Cerrados, que encontrou maior frequência para o descritor na classe verde arroxeada (44\%), e também para Barbosa (2013), que obteve maior frequência nesta mesma classe
(62,97\%) na caracterização de 27 clones no estado da Bahia.

descritor pubescência do broto apical apresentou baixa variação de percentual nas duas classes fenotípicas, prevalecendo ainda a ausência de pilosidade (54,42\%). $\bigcirc$ mesmo ocorreu para Vieira et al (2008), onde 61\% de seus acessos não apresentaram pubescência nos brotos apicais. Já para Barbosa (2013), 59,26\% dos genótipos avaliados apresentaram pilosidade.

Quanto a forma do lóbulo central, obtevese maior frequência para a classe lanceolada (50,18\%), corroborando com os resultados obtidos por Vieira et al. (2008) e Barbosa (2013).

Na avaliação de cor e posição do pecíolo, houve dispersão entre as classes assegurando maior frequência para as de coloração vermelho (31,10\%) e verde avermelhado (28,62\%), e pecíolo inclinado para cima (39,58\%) e na horizontal (32,86\%). Em relação à cor, Vieira et al (2008) também obteve dados semelhantes nas classes cor do pecíolo vermelho (27\%) e verde avermelhado (21\%), diferindo dos dados obtidos por Barbosa (2013), onde a coloração do pecíolo apresentou-se predominantemente verde avermelhado (29,63\%) e com ampla variação 
para as demais classes. Já para o descritor

posição do pecíolo, Vieira et al (2008) e

Barbosa obtiveram $79 \%$ e $62,95 \%$ respectivamente, de frequência para a classe horizontal.

Tabela 2. Descritores, classes fenotípicas e frequência em cada classe para os genótipos avaliados.

\begin{tabular}{|c|c|c|}
\hline Descritores & Classes & Frequência (\%) \\
\hline \multirow{4}{*}{ Cor da folha apical } & Verde clara & 31,45 \\
\hline & Verde escura & 14,13 \\
\hline & Verde arroxeada & 37,81 \\
\hline & Roxa & 16,61 \\
\hline \multirow{2}{*}{ Pubescência do broto apical } & Ausente & 54,42 \\
\hline & Presente & 45,58 \\
\hline \multirow{10}{*}{ Forma do lóbulo central } & Ovóide & 0,71 \\
\hline & Elíptica-lanceolada & 32,86 \\
\hline & Obovada-lanceolada & 1,41 \\
\hline & Oblongo-lanceolada & 1,41 \\
\hline & Lanceolada & 50,18 \\
\hline & Linear & 4,24 \\
\hline & Pandurada & 1,06 \\
\hline & Linear-piramidal & 1,77 \\
\hline & Linear-pandurada & 6,36 \\
\hline & Linear-hostatilobada & 0,00 \\
\hline \multirow{6}{*}{ Cor do pecíolo } & Verde amarelado & 4,95 \\
\hline & Verde & 4,59 \\
\hline & Verde avermelhado & 28,62 \\
\hline & Vermelho esverdeado & 12,72 \\
\hline & Vermelho & 31,10 \\
\hline & Roxo & 18,02 \\
\hline \multirow{3}{*}{ Cor do córtex do caule } & Amarelo & 13,43 \\
\hline & Verde claro & 57,24 \\
\hline & Verde escuro & 29,33 \\
\hline \multirow{7}{*}{ Cor externa do caule } & Laranja & 11,31 \\
\hline & Verde amarelado & 6,01 \\
\hline & Dourado & 0,71 \\
\hline & Marrom claro & 35,34 \\
\hline & Prateado & 5,30 \\
\hline & Cinza & 15,90 \\
\hline & Marrom escuro & 25,44 \\
\hline \multirow{3}{*}{ Comprimento da filotaxia } & Curto $(<8 \mathrm{~cm})$ & 3,89 \\
\hline & Médio (8-15cm) & 63,96 \\
\hline & Longo (>15cm) & 32,16 \\
\hline
\end{tabular}




\begin{tabular}{|c|c|c|}
\hline \multirow{4}{*}{ Cor da folha desenvolvida } & Verde clara & 28,27 \\
\hline & Verde escura & 60,42 \\
\hline & Verde arroxeada & 11,31 \\
\hline & Roxa & 0,00 \\
\hline \multirow{4}{*}{ Número de lóbulos } & Três & 0,00 \\
\hline & Cinco & 15,55 \\
\hline & Sete & 76,33 \\
\hline & Nove & 8,13 \\
\hline \multirow{4}{*}{ Cor da epiderme do caule } & Creme & 30,04 \\
\hline & Marrom claro & 51,94 \\
\hline & Marrom escuro & 13,43 \\
\hline & Laranja & 4,59 \\
\hline \multirow{2}{*}{$\begin{array}{l}\text { Hábito de crescimento do } \\
\text { caule }\end{array}$} & Reto & 86,22 \\
\hline & Zig-zag & 13,78 \\
\hline \multirow{3}{*}{$\begin{array}{c}\text { Cor dos ramos terminais nas } \\
\text { plantas adultas }\end{array}$} & Verde & 29,68 \\
\hline & Verde arroxeado & 67,49 \\
\hline & Roxo & 2,83 \\
\hline \multirow{4}{*}{ Cor da nervura } & Verde & 56,89 \\
\hline & Verde vermelho em - da metade do lóbulo & 32,16 \\
\hline & Verde vermelho em + da metade do lóbulo & 10,60 \\
\hline & Toda vermelha & 0,35 \\
\hline \multirow{4}{*}{ Posição do pecíolo } & Inclinado para cima & 39,58 \\
\hline & Horizontal & 32,86 \\
\hline & Inclinado para baixo & 10,60 \\
\hline & Irregular & 16,96 \\
\hline \multirow{2}{*}{$\begin{array}{c}\text { Proeminência das cicatrizes } \\
\text { foliares }\end{array}$} & Sem proeminência & 0,00 \\
\hline & Com proeminência & 100,00 \\
\hline \multirow{2}{*}{ Comprimento das estípulas } & Curtas & 73,50 \\
\hline & Longas & 26,50 \\
\hline \multirow{4}{*}{ Hábito de ramificação } & Ereto & 6,71 \\
\hline & Dicotômico & 74,20 \\
\hline & Tricotômico & 16,96 \\
\hline & Tetracotômico & 2,12 \\
\hline \multirow{8}{*}{ Nível de ramificação } & 0 & 6,71 \\
\hline & 1 & 12,37 \\
\hline & 2 & 23,32 \\
\hline & 3 & 22,61 \\
\hline & 4 & 18,73 \\
\hline & 5 & 13,78 \\
\hline & 6 & 1,77 \\
\hline & 7 & 0,71 \\
\hline \multirow{4}{*}{ Tipo de planta } & Compacta & 59,01 \\
\hline & Aberta & 3,53 \\
\hline & Guarda-sol & 25,44 \\
\hline & Cilíndrica & 12,01 \\
\hline
\end{tabular}


A coloração das folhas desenvolvidas apresentou-se predominantemente $(60,42 \%)$ verde escura assim como para Vieira et al (2008) e Barbosa (2013).

Na quantificação do número de lóbulos, Barbosa (2013) apresenta dados de $66,67 \%$ de genótipos com cinco lóbulos foliares, seguidas pela ocorrência de sete lóbulos 33,33\%, diferindo dos resultados obtidos por Vieira et al (2008) onde $66 \%$ dos acessos possuem sete lóbulos, e com dados obtidos neste estudo que apresentou $76,33 \%$ de frequência também para a classe com sete lóbulos.

Barbosa (2013), obteve maior percentual na classe cor dos ramos terminais nas plantas adultas verde arroxeado (59,26\%), o que segundo a autora, evidencia a presença de antocianina que pode ser considerada, neste caso, uma característica evolutiva de adaptação a estresses bióticos e abióticos. Este estudo evidenciou a presença de $67,49 \%$ de plantas adultas com ramos terminais de coloração verde arroxeado, e Vieira et al (2008) obteve frequência de 73\% nesta mesma classe.
Obteve-se frequência igual a 56,89\% de plantas com coloração verde na nervura das folhas. Barbosa (2013) apresentou dados de que 88,89\% dos genótipos avaliados apresentaram esta coloração nas nervuras.

Para o descritor proeminência das cicatrizes foliares, toda a população avaliada apresentou proeminência. $\bigcirc$ mesmo ocorreu para Barbosa (2013) que obteve frequência de 88,89\% de genótipos com cicatrizes proeminentes.

Dos descritores utilizados na caracterização do caule, as seguintes classes fenotípicas se destacaram: cor externa do caule marrom claro (35,34\%) e marrom escuro $(25,44 \%)$, cor do córtex do caule verde claro (57,24\%), cor da epiderme do caule marrom clara (51,94\%), filotaxia de comprimento médio (63,96\%), hábito de crescimento reto (86,22\%), hábito de ramificação dicotômico (74,20\%), e plantas do tipo compactas (59,01\%). Quanto ao nível de ramificação, a população se apresentou consideravelmente dispersa, com maior número de plantas com dois (23,32\%), três (22,61\%) e quatro níveis (18,73\%). 
Barbosa (2013), obteve em suas avaliações maior frequência de genótipos com cor externa de caule prateado (33,33\%), cor do córtex verde escuro (81,48\%), cor da epiderme laranja $(51,85)$ hábito de crescimento reto em sua totalidade, hábito de ramificação dicotômico $(66,67)$, nível de ramificação de 2 e 3 (40,74\% cada), plantas do tipo compacta $(37,04 \%)$ e comprimento da filotaxia em nível médio (62,96\%).

Já no trabalho desenvolvido por Vieira et al (2008), apresentaram maior frequência as classes: cor externa do caule prateado (27\%), cor do córtex verde escuro (56\%), cor da epiderme marrom escuro (64\%), hábito de crescimento reto em sua totalidade e plantas do tipo guarda-sol (45\%), somente equiparando a classe comprimento da filotaxia média (78\%), o que demonstra não haver relação direta entre caracteres morfológicos de folhas e caule.

Foram analisados também, dados quantitativos apresentados da tabela 3 juntamente com suas medidas de dispersão.

Tabela 3. Estatísticas descritivas para os descritores utilizados na avaliação dos genótipos.

\begin{tabular}{lccccc}
\hline \multicolumn{1}{c}{ Descritores } & Média & Desvio Padrão & Valor mínimo & Valor máximo & $\begin{array}{c}\text { Coeficiente de } \\
\text { variação (\%) }\end{array}$ \\
\hline Comprimento lóbulo (cm) & 12,58 & 3,06 & 4 & 21 & 24,32 \\
Largura lóbulo (cm) & 3,37 & 1,11 & 1 & 6 & 32,94 \\
Relação C/L lóbulo & 4,29 & 2,6 & 2,25 & 17,00 & 60,61 \\
Comprimento pecíolo $(\mathrm{cm})$ & 16,58 & 4,71 & 3,5 & 30 & 28,41 \\
Altura (m) & 1,46 & 0,43 & 0,35 & 2,7 & 29,45 \\
Altura 1a ramificação $(\mathrm{cm})$ & 30,08 & 35,23 & 1 & 180 & 117,12 \\
\hline
\end{tabular}

O descritor Comprimento do lóbulo obteve menor dispersão dos dados em relação aos demais descritores. Sua média é de 12,58 cm. Barbosa (2013) obteve média igual a 10,63 cm.
Os descritores Altura da primeira ramificação Relação comprimento/largura do lóbulo apresentaram os maiores índices de dispersão dos dados analisados. 


\section{CONCLUSÃO}

A população gerada a partir do cruzamento de genótipos resulta em alta variabilidade fenotípica, sendo possível afirmar que somente a característica presença de cicatrizes foliares foi homogênea para todos os genótipos estudados. Não existe relação direta entre características morfológicas foliares e de caule. Os descritores utilizados possuem deficiência de classes que melhor representem as características de cada indivíduo, desta forma impossibilitando o estabelecimento de marcadores morfológicos específicos.

\section{AGRADECIMENTOS}

Ao Programa de Educação Tutorial Conexões de Saberes de Estudos Interdisciplinares: Comunidades do Campo/CFI/UFOPA e ao Fundo Nacional de Desenvolvimento da Educação - FNDE.

\section{REFERÊNCIAS}

ANÁLISE DA CONJUNTURA AGROPECUÁRIA, Mandioca - Safra 2015/16. SEAB/DERAL, 2015.

ARAÚJO, R.M.; ARRUDA JUNIOR, S. Cultura da mandioca: estudo de caso no agreste potiguar à luz dos relacionamentos inter atores. HOLOS, ano 29, vol. 6, p. 52-72, 2013.

BARBOSA, G. M. Caracterização morfofisiológica de clones de mandioca em Cândido Sales-BA. Vitória da Conquista, BA: UESB, 2013. $141 \mathrm{p}$

CAMPOS, A.L. et al, Avaliação de acessos de mandioca do banco de germoplasma da UNEMAT Cáceres - Mato Grosso. Revista Trópica - Ciências Agrárias e Biológicas, v. 4, n. 2, p. 44-54, 2010.

BURLE, M. L.; OLIVEIRA, M. S. P. Manual de curadores de germoplasma - vegetal: Caracterização morfológica. Brasília, DF: Embrapa Recursos Genéticos e Biotecnologia; Belém, PA: Embrapa Amazônia Oriental, 2010. 15 p

FUKUDA, W. M. G.; GUEVARA, C. L. Descritores morfológicos e agronômicos para a caracterização de mandioca (Manihot esculenta Crantz). Cruz das Almas: EMBRAPA-CNPMF, 1998, 38p. (EMBRAPA-CNPMF, Documentos, 78).

GAMA, T. S. S.; LUCAS, F. C. A.; LOBATO, G. J. M. Morfologia dos grãos de amido de cultivares de mandioca (Manihot esculenta Crantz) em Caxiuanã, Pará, Brasil. Scientia Amazonia, v. 4, n. 3, p. 6368, 2015.

HENRIQUE, C. M.; CEREDA, P.M.; SARMENTO, S. B. S. Características físicas de filmes biodegradáveis produzidos a partir de amidos modificados de mandioca. Ciência e Tecnologia de Alimentos, Campinas, vol. 28, n. 1, p. 231240, 2008.

LARA, A. C. C.; BICUDO, S. J.; BRACHTVOGEL, E. L.; ABREU, M. L. de; 
CURCELLI, F. Melhoramento genético da cultura da mandioca (Manihot esculenta Crantz). Revista Raízes e Amidos Tropicais, Botucatu, v. 4, p. 54-64, 2008.

MEZETTE, T.F; CARVALHO, C. R. L.; MORGANO, M. A.; SILVA, M. G. da; PARRA, E. S. B.; GALERA, J. M. S. V.; VALLE, T. L. (3 Seleção de clones-elite de mandioca de mesa visando a características agronômicas, tecnológicas e químicas. Bragantia, Campinas, v. 68, n. 3, p. 601-609, 2009.

NICK, C.; CARVALHO, S. P.; JESUS, A. M. S.; CUSTÓDIO, T. N.; MARIM, B. G.; ASSIS, L. H. B. Divergência genética entre subamostras de mandioca. Bragantia, Campinas, v. 69, n. 2, p. 289-298, 2010.

NOLASCO, C. A., Caracterização citogenética e morfológica de híbridos de mandioca (Manihot esculenta). Vitória da Conquista: UESB, 2011

SILVA, R. M.; BANDEL, G.; FARALDO, M. I. F.; MARTINS, P. S. Biologia reprodutiva de etnovariedades de mandioca. Scientia Agrícola, v.58, n.1, p.101-107, jan. /Mar. 2001.

TEIXEIRA, P.R.G.; VIANA, A. E. S.; CARDOSO, A. D.; LOPES, S. C.; GUIMARÃES, D. G.; ANDRADE, A. C. B. Características morfológicas de quatro variedades de mandioca de mesa cultivadas em Vitória da Conquista - BA.

Revista Raízes e Amidos Tropicais, Botucatu, v. 10, n. 1, p. 1-8, 2014.

VIEIRA, E. A.; FIALHO, J. F.; FALEIRO, F. G.; BELLONI, G.; FONSECA, K. G.; CARVALHO, L. J. C. B.; SILVA, M. S. Caracterização molecular e variabilidade genética de acessos elite de mandioca para fins industriais. Ciência Rural, Santa Maria, v. 40, n. 12, p. 2467-2471, 2010.

VIEIRA, E. A.; FIALHO, J. F.; SILVA, M. S.; FUKUDA, W. M. G.; FALEIRO, F. G. Variabilidade genética do banco de germoplasma de mandioca da Embrapa Cerrados acessada por meio de descritores morfológicos. Científica, Jaboticabal, v. 36, n. 1, p. 56-67, 2008.

ZUIN, G. C.; VIDIGAL FILHO2, P. S.; KVITSCHAL, M. V.; GONÇALVES-VIDIGAL, M. C.; COIMBRA, G. K. Divergência genética entre acessos de mandioca-demesa coletados no município de Cianorte, região Noroeste do Estado do Paraná. Semina: Ciências Agrárias, Londrina, v. 30, n. 1, p. 21-30, 2009. 